\title{
O SENTIDO E O PROBLEMA DO "SEPARATISMO MODERADO": POR UMA CONTRIBUIÇÃO SOCIOLÓGICA À ANÁLISE DA RELIGIÃO NO ESPAÇO PÚBLICO ${ }^{1}$
}

Luca Diotallevi

\section{A EVOLUÇÃO DAS RELAÇÕES ESTADO/IGREJA COMO ELEMENTO CRUCIAL DAS TRANSFORMAÇÕES DO ESPAÇO PÚBLICO}

Os estudos sociológicos dedicados às relações Estado/Igreja e relativos às últimas duas décadas demonstram uma forte convergência em sua substância. Mesmo que anteriormente numerosos trabalhos de caráter predominantemente teórico (Luhmann, 1977) já tenham assinalado a oportunidade de rever a compreensão então dominante da secularização como hegemonia social da política e, consequentemente, como marginalização da religião, o volume publicado por J. Casanova (2000), no início dos anos 90, é ainda, na maior parte dos casos, considerado como o ponto de conversão. É a ele que se atribui o mérito de ter reconhecido a retomada da influência da religião na política também nas sociedades "ocidentais avançadas". Era inevitável que tal retomada fosse destinada a refletir sobre o equilíbrio entre Estado e Igreja.

Os modelos teóricos utilizados posteriormente para reconstruir e interpretar esta inversão de tendência são diferentes entre eles, bem como são diferentes as etiquetas cunhadas para identificar o tipo de relação Estado/ Igreja que, aos poucos, mais claramente, começou a predominar. Apesar de tanta variedade é evidente um grande consenso sobre o declínio do modelo separatista e a crescente difusão de relações de cada vez maior cooperação entre Estado e Igreja.

1 Tradução: Cláudia Mendonça Scheeren, Jane Diogo Trein e Priscila Silveira Saraiva.

2 Professor da Universidade de Roma TRE. Contato: luca.diotallevi@uniroma3.it 
Recentemente Alfred Stepan (2011) insistiu no "multiple secularism" (múltiplo secularismo) - com referência precisa às múltiplas modernidades "multiple modernities" (Einsenstadt). De fato, o modelo separatista, que geralmente justifica a classificação de certo tipo de relação Estado/Igreja como laicidade ${ }^{3}$, já deixou de ser algo mais que uma exceção. A maior parte dos casos nacionais considerados por Stepan, inclusive fora dos perímetros das sociedades ocidentais, não conheceu ou repudiou o separatismo laico ("separatist secularismo") em vantagem de alguma modalidade de maior cooperação entre Estado e agentes religiosos (caso a caso definido por - "positive accomodation - positive cooperation - principled distance" - ou por "respect all", ou ainda em alguma forma de verdadeiro "establishmentarianism"). (Palavras em destaque: grifos do autor).

T. Modood reconstrói o mesmo processo e um resultado muito semelhante, contrapondo a um declínio das áreas caracterizadas por 'secularismo radical' ("radical secularism") um aumento daquelas influenciadas por um 'secularismo moderado' (2011a). Na crítica a Bhargava, Modood, referindo-se aos dois clássicos exemplos de separatismo, escreve que não apenas "[...] Estados Unidos e França não são o melhor que o ocidente tem para oferecer" em matéria de relação Estado/Igreja, mas que seu separatismo já não desenvolve mais a função de modelo-guia (2012b, p. 65). Na mesma linha, e ainda antes, J. T. S. Madeley, referindo-se às transformaçōes conhecidas pela Europa no campo das relaçôes Estado/Igreja de 1980 a 2000 escreve: "Antidisestablishmentarianism 4 , que por muito tempo tinha acreditado que fosse apenas a palavra mais longa da língua inglesa - e, talvez, uma das com significado mais obscuro, já pode ser considerado um fenômeno social muito mais robusto do que se presumia no passado" (2013, p. 17) - a respeito

3 Utiliza-se o termo secular na literatura de língua inglesa. Em francês, o termo é normalmente traduzido para lä̈cité.

4 O desmantelamento de cada forma de religião de Estado, nota do tradutor. 
do que foi possível observar entre 1900 e $1970^{5}$ (2009, p. 278-280. Ver também Finke (2013), Rahman (2013). Também é semelhante o resultado do trabalho de J. Haynes (2010). Os resultados de outro reconhecimento da escala mundial também levam J. Fox a concluir não apenas que: "SRAS [um alto nível de separação nas relações entre religião e Estado] é exceção enquanto GIR [um significativo envolvimento do governo em questôes religiosas] é a norma” (2006, p. 561), mas ainda que “[...] os processos de modernização social estejam estatisticamente associados a uma alta pontuação de GIR". De resto, Casanova (2000, p. 1058) e Stepan (2011) insistem na inutilidade, se não no verdadeiro e real dano, do "secularism" para a democracia e para o seu desenvolvimento. (Palavras em destaque: grifos do autor).

\section{ALGUMAS CRÍTICAS ÀS RECONSTRUÇÕES PREDOMINANTES}

A tendência geral, que foi há pouco recordada, dificilmente pode ser colocada em dúvida, mas não a sua interpretação e a tipologia com a qual foi analisada. Essa última, inclusive, baseia-se em geral no uso de alguma tipologia incluída em uma série de pares de categorias que podem, mais ou menos, se sobrepor, por exemplo: secularismo ou separatismo radical versus secularismo ou separatismo moderado. No entanto, o resultado de seu emprego deixa alguma incerteza. Ao menos uma incerteza de natureza formal e uma de natureza substancial.

Sob o perfil metodológico, convém duvidar da utilidade e talvez da coerência de uma categoria quando nela se encontram muitos casos. $\mathrm{Ou}$ seja, é oportuno sobretudo quando - como para alguns dos trabalhos recordados - trata-se de uma das únicas duas categorias de uma classificação binária. E é exatamente isso que se verifica com a categoria de "moderate secularism". De acordo com dados de Fox (2006, p. 545), definir-se-iam

5 Paralelamente ao processo de declínio da redução dos agentes públicos a poucos sujeitos de tipo estatal (Cassese, 2013, p. 15-16). 
nesses termos - de acordo com os cálculos - de $70 \%$ a $90 \%$ dos casos estudados em nível mundial. Como notam R. Ahdar e I. Leigh (2005, p. 97): “[...] 'muitos regimes' e bem diferentes uns dos outros - establishment atenuado, pluralismo, neutralidade substancial - obtêm pontuação elevada na escala que mede a interação e a cooperação entre governo e comunidades religiosas" (ver também Doe, 2011, p. 39). (Palavras em destaque: grifos do autor).

Porém ainda mais consistente é a segunda incerteza. Na maior parte dos casos, os separatismos norte-americano e francês terminam na mesma categoria, e muitas vezes sozinhos ou quase (ver, entre outros, Stepan, 2011, p. 114; Fox, 2006; Jensen, 2011, p. 16). E não é tudo, deste pequeno grupo, os dois separatismos deveriam dividir o papel de protótipo. As diferenças entre a situação e o regime francês e norte-americano no que tange à relação entre poderes religioso e político, e ainda mais em geral, as mais diversas condições de acesso dos agentes religiosos ao espaço público em cada um dos casos, constituem um dado tão notório ao ponto de não necessitar ser ilustrado aqui pela enésima vez. A controvérsia relativa à possibilidade de usar ou não publicamente roupas ou sinais que expressam uma identidade religiosa resume suficientemente aquelas principais diferenças. Neste caso, o mesmo comportamento individual cria sérios problemas ao regime de laïcité e não cria nenhum ao regime de religious freedom, fundado sob duas cláusulas religiosas da primeira emenda constitucional dos Estados Unidos da América. Ao contrário, em algum aspecto, pelo menos, exprime inclusive uma das condiçóes de sobrevivência desse último.

Em suma, se para interpretar a evolução das relações Estado/Igreja recorre-se aos pares de categoria como "separatismo radical" versus "separatismo moderado" (ou equivalentes) encontra-se a seguinte situação: se a primeira categoria, mesmo reunindo poucos casos, acaba por agrupar exemplos - como o francês e o norte-americano - muito diferentes entre eles, é muito provável que o mesmo se verifique quando usada a segunda categoria, porque nessa se encerra um número muito maior de casos e - simplesmente observando a primeira - conservam-se os elementos defi- 
nidores de base. É, por isso, provável que o "separatismo moderado" tenha uma utilidade analítica não maior ou talvez até mesmo menor que a do "separatismo radical" ${ }^{6}$.

Por fim, não falta quem considere bastante vaga a noção tradicional de "separatismo" e, por isso, pouco capaz de distinguir e identificar coisa alguma (Casanova, 2009, p. 1061-1062; Kuru, 2007, p. 569-572). Inclusive, esta categoria parece ter um significado ambíguo. Às vezes, é capaz de significar o contrário. Como mostra Stepan (2011, p. 118-120), em alguns casos, a lä̈cité, como forma típica do "separatismo autoritário", não separa realmente, ao invés disso, subordina e até engloba (Valasik, 2010, p. 145; Klausen, 2009, p. 291), quando mesmo tende a fundir, como no caso da religion civile rousseauniana fundadora de cada religião política moderna (1974, p. 131; Nancy, 2007). Assim, no âmbito do separatismo radical, a laïcité acaba representando não apenas uma exceção na exceção, mas também uma exceção em crise. É isso que, ao final, de comum acordo, testemunham os seus críticos e os seus defensores (Modood, 2012, p. 139-140; Commissione Stasi, 2004, p. 9) 7 .

Uma crítica análoga dirige-se à categoria de neutralidade (Ahdar Leigh, 2005, p. 87). Essa categoria pode de fato revelar-se sinônimo de hegemonia da política sobre a religião, particularmente no caso da "neutralidade formal" (“formal neutrality”) (Monsma, 2000).

Definitivamente, a interpretação da tendência evolutiva que nas últimas décadas afirmou-se no âmbito das relações Estado/Igreja, definida como "separatismo moderado" (ou em um termo análogo), requer um aprofundamento crítico.

\footnotetext{
${ }^{6}$ Uma assimilação análoga é operada por J. Maclure e C. Taylor (2013) sob o título de "regimes de laicidade".

7 Para outras posições externas e isoladas, ver Baubérot (2008).
} 


\section{UMA DIFERENÇA NEGADA}

Essa contribuição pretende oferecer à discussão uma hipótese capaz de contribuir com o aprofundamento crítico há pouco citado. A formulação de tal hipótese inicia-se com a discussão da assimilação dos separatismos francês e norte-americano.

A partir da hipótese que pretendemos avançar, é possível encontrar traços recentes na literatura sociológica, mas em termos recém-mencionados $^{8}$. Como escrito por J. Beckford, por exemplo, entre a laïcité e a religious freedom norte-americana: "[...] as diferenças prevalecem efetivamente muito acima das semelhanças" (2004, p. 31) e - acrescenta - os sociólogos "[...] não estão em nível de levar adequadamente em conta o impacto da laïcité como ideologia” (p. 27, grifo do autor). O mesmo Modood (2009) convidou a indagar a diferença entre os regimes das relações Estado/Igreja francês, norte-americano e britânico, a fim de captar de modo mais preciso o espírito do "secularismo moderado" ("moderate secularism").

Enfim, o que se tentará é colocar em evidência uma diferença-chave entre os regimes francês e norte-americano, uma diferença capaz de construir uma razão muito forte de insatisfação para a assimilação destes dois separatismos. Porém, nas páginas seguintes, não se gostaria de limitar à simples indicação dessa diferença. Gostaria de ir além e mostrar o quanto a hipótese crítica que se impulsiona por essa diferença é muito provavelmente cheia de importantes desenvolvimentos.

Partindo da crítica da assimilação entre os separatismos francês e norte-americano, será possível colocar em primeiro lugar e focar em uma diferença funcional elaborando um reordenamento mais útil da megacategoria do "secularismo moderado". À luz dessa diferença, pode-se compreender um pouco melhor porque podem ser muitas e, muito diferentes, as formas de cooperação Estado/Igreja, não todas, por exemplo, desenvolvendo-se sobre

8 A exposição e a discussão desta tese foram apresentadas em Diotallevi $(2007,2010)$. 
uma base de paridade 9 . Em segundo lugar, a partir da mesma perspectiva, é facilitada uma compreensão da identidade e da tradição europeia no âmbito das relações Estado/Igreja, diferente da ainda predominante entre opinião pública e agentes políticos. Essencialmente, torna-se mais fácil colocar em discussão a remoção do caso britânico e, portanto, também recolher as oscilaçóes das intervenções, neste campo, de um complexo de agentes, expressão da União Europeia.

\section{LAÏCITÉ FRANCESA E RELIGIOUS FREEDOM NORTE-AMERICANA}

Como dito anteriormente, não poucos autores sublinharam que há muitos modos diferentes para separar Igreja e Estado (ou melhor: política e religião, ou seja, as formas sociais de uma e de outra). Isso vale, antes de tudo e talvez mais do que nunca, no caso dos regimes francês e norte-americano (Whitman, 2011, p. 239 et seq.).

A operação que é proposta aqui procura, em primeiro lugar, individualizar um critério para distinguir diferentes modelos de separatismo depois de assumir este tipo de regime de relação entre Estado e Igreja, sobretudo como um efeito, e não somente como causa. Propõe-se na análise a volta para a questão mais geral do tipo de diferenciação social que se afirma em um determinado contexto social e, neste quadro, voltar para a forma assumida pelo sistema político: sua polity (Madeley, 2009, p. 174-175; Jepperson, 2002, p. 67-71). É o mesmo Casanova quem sugere uma pergunta crucial: entre Estado e Igreja, "[...] como e por quem os limites são traçados?", e prossegue, "[...] o secularismo político facilmente degenera em secularismo ideológico quando o político atribui-se um caráter absoluto, de soberania, quase sacral, de quase transcendência ou quando a razão laica atribui a si

9 Pensemos aos modelos 2, 3 e 4 em Stepan (2011, p. 139). Eles individualizam regimes muito diferentes, mas todos são classificados como um posterior "secularismo moderado". 
mesma e se cobre com um manto de racionalidade e de universalidade, enquanto declare o 'religioso' por sua essência irracional, particular e intolerante (ou não liberal)" (2009, p. 1058).

Na verdade, quando pergunta-se - como faz R. L. Jepperson (2002) - se o princípio de organização de uma sociedade é corporativo ou associativo e - ao mesmo tempo - se o nível de institucionalização da collective agency é elevado ou modesto, ou qual é o modo de auto-organização da política e de diferenciação dessa para o resto da sociedade, termina-se por constatar facilmente que os casos francês e norte-americano acabam em células bem diferentes da matriz.

É necessário olhar para as formas de diferenciação da sociedade desenvolvidas nos diversos contextos para melhor compreender as diferentes formas de separatismo nas relações Estado/Igreja. Z. Enyedi sugere impulsionar a análise nesta mesma direção, o que se trata de reconhecer são as diversas variantes e o andamento não monótono da secularização compreendida como diferenciação institucional (2003, p. 219).

Deste mesmo ponto de partida, pode-se aceitar o desafio interpretativo dirigido por aqueles que, orientando-se diferentemente, propóem enquadrar a questão da diversidade entre separatismos a partir do confronto entre teorias da modernização (Kuru, 2007, p. 572) ou a partir da diversidade entre noções de ordem pública - e pela consequente diversidade dos papéis que em cada caso é chamado a desenvolver o sistema judiciário, as suas cortes e as suas decisões - (Ferrari, 1999).

Para construir e desenvolver a hipótese do que foi dito, será necessária a teoria da diferenciação social elaborada por N. Luhmann (1997, p. 743 et seq.) e da compreensão dos direitos fundamentais que constituem um importante elemento seu (Luhmann, 2001, 1990, 1995). Com isso, seguir-se-á por um caminho já traçado por temas estreitamente ligados - aos demais - por P. Beyer (2012) e P. Gorski (2000). 


\section{UM INDÍCIO CRUCIAL}

Para tal tarefa (reconstruir os dois separatismos em níveis e formas diversas de diferenciação social), um bom ponto de partida é oferecido de forma diferente da qual o regime francês de lä̈cité e o norte-americano de religous freedom entendem a relação entre liberdade religiosa e liberdade de consciência (Diotallevi, 2010, p. 80 et seq.). Resumindo, no caso da lä̈cité, a liberdade religiosa é um dos possíveis conteúdos da liberdade de consciência, ou seja, é a última que garante a primeira. Por outro lado, no regime norte-americano de religious freedom, a liberdade religiosa vem a ser a primeira garantia da liberdade de consciência. No caso da lä̈cité, a consciência é um espaço privado que o Estado deixa livre para exercitar as próprias eventuais preferências religiosas. A expressão pública de tais preferências, ao contrário, é estreitamente regulada por parte do próprio Estado. De modo bem diferente é o caso da religious freedom, sobretudo na prática pública da religião, não apenas através dos ritos, mas também através de obras não religiosas religiosamente inspiradas (políticas, econômicas, educativas etc.), garantida ao indivíduo pela temida eventualidade de que o poder político ocupe todo o espaço público. Desse modo, não exclusivamente, mas antes de mais nada através de obras (religiosas e não religiosas) da religião nos Estados Unidos, depois de 1791 definitiva e irreversivelmente federalista, vem impedido o constituir-se do Estado, no sentido europeu-continental do termo (McConnel, 2009; Witte; Nichols, 2011, p. 288; Poggi, 2007; Cassese, 1998).

Não por acaso, os regimes de läicité e religous freedom tratam de modo muito diferente a noção de autonomia dos sujeitos religiosos (Stepan, 2001, p. 217; Ahdar Leigh, 2005, p. 92; Monsma, 2009, p. 182; Doe, 2011, p. 112-120). Joga-se uma partida crucial em torno dos graus e das formas de reconhecimento da autonomia dos agentes religiosos. A diferença entre regimes de lä̈cité e religious freedom depende de modo decisivo do resultado dessa partida. Esse resultado está entre os fatores que mais influenciam a colocação que um país acaba tendo em uma célula ou em outra da matriz 
antes citada e gerada pelas combinaçôes (quatro) de baixo ou alto nível de institucionalização da public agency e do princípio organizacional corporativo ou associativo da sociedade.

Recorrendo a uma metáfora geométrica, pode-se dizer que as duas "paredes de separação" (walls of separation) entre Estado e Igreja, aquela erigida pela lä̈cité e aquela erigida pela religious freedom, não acabam sendo passíveis de sobreposição, mas até mesmo aparecem ortogonais uma em relação à outra. A wall of separation da religious freedom corre através do espaço público, não apenas garantindo um espaço público à religião (para as suas obras e também às não religiosas), mas ainda antes garantindo ao próprio espaço público certa conformação, graças a alguns dos efeitos das obras da religião. $\mathrm{O}$ que também se quer garantir pelo regime de religious freedom é justamente a impossibilidade de se constituir um Estado com monopólio do espaço público por parte da política. Resumindo, enquanto no caso da laicidade o espaço público resulta homogêneo e dominado pelo poder político, no caso da religious freedom o espaço público resulta, ao contrário, heterogêneo e subtraído de qualquer hegemonia (fig. 1). O regime da laïcitéé, então, um elemento crucial da polity de uma state society, enquanto o regime da religious freedom é um elemento crucial da polity de uma stateless society.

\section{UM AUXÍLIO ANALÍTICO POSTO À DISPOSIÇÃO POR LUHMANN}

Como foi visto, na base do regime norte-americano de religious freedom, está a atribuição de valor constitucional - com a primeira emenda constitucional aprovada em 1791 - a dois princípios que podem até aparecer em conflito um com o outro e assimétricos em suas reivindicações: disestablishment e free exercise (Monsma, 2000, p. 13, p. 32-37 ${ }^{10}$ ). Justamente

${ }^{10} \mathrm{O}$ qual, entre outros, para individualizar os campos de ação dos dois princípios, recorre a um esquema funcional muito semelhante ao luhmanniano (Monsma, 2000, p. 33).

Debates do NER, Porto Alegre, ANo i6, N. 27, P. I9-48, JAN./Jun. 2015 
essa contradição - muito mais que somente aparente - não deve ser tratada como se fosse um obstáculo, mas como um traço precioso.

Exatamente sobre a dificuldade de interpretar esta oposição entre disestablishment e free exercise pode tornar útil o recurso à compreensão sociológica dos direitos fundamentais do indivíduo elaborada por N. Luhmann (2003, p. 57-62, p. 124 et seq., p. 154 et seq.; Philippopoulos-Mihailopoulos, 2011, p. 154). Os Grundrecht-ou seja, os direitos fundamentais - aparecem pelo ponto de vista sociológico como instituições que nenhum subsistema social está em condições de produzir ex novo, mas que estes sistemas funcionalmente especializados, sobretudo o político e o judiciário, podem vir a manter, em função de uma operação típica: o acoplamento estrutural (structural coupling, strukturelle Kopplung) (Luhmann, 1997, p. 778 et seq., p. 782-783; 2005, p. 325-328; Philippopoulos-Mihailopoulos, 2011, p. 130). A função específica dessas instituições, ou seja, a função dos direitos fundamentais que a análise sociológica consegue reunir é a de garantir e eventualmente incrementar a primazia da diferenciação por funções da sociedade em relação a cada outro tipo de diferenciação social. Aceitando e sustentando aquelas instituições que são os Grundrechte, cada um dos subsistemas sociais - o político, por exemplo - por um lado deixando amplo espaço de ação ao próprio exterior (se autolimita e não politiza o resto da sociedade) e, ao mesmo tempo, se protege de uma excessiva influência por parte dos ressentimentos gerados em seu ambiente pelos outros sistemas sociais (não perde a própria elevada independência), e, por outro, constrói socialmente e respeita a liberdade e dignidade dos indivíduos (mais precisamente: garante uma condição social necessária para a autorrepresentação de cada indivíduo como única personalidade) (Luhmann, 2002, p. 108 et seq.). Um subsistema especializado e funcionalmente diferenciado da sociedade - assumindo como instituições os direitos fundamentais do indivíduo - não renuncia à própria autorreferencialidade e, consequentemente, ao seu elevado grau de autonomia, mas combina estas duas propriedades com um elevado grau de diferenciação social de tipo funcional e com um igualmente elevado grau de diferenciação do domínio do social pelo domínio pessoal. 
Fala-se de duas categorias de direitos fundamentais. Nestes casos, a função da primeira categoria é geralmente identificada nos termos dos "direitos de liberdade" e a segunda nos termos dos "direitos de igualdade". Segundo a proposta analítica de Luhmann, esta duplicidade depende do duplo risco para a liberdade e a dignidade individual produzido pelo processo de diferenciação para especialização dos subsistemas sociais, nesse caso, do subsistema político. De fato, cada decisão política poderia forçar ou até mesmo obrigar o único indivíduo a agir de modo inadequado em grau e formas definidos pela diferenciação social. Por outro lado, cada decisão única do subsistema político poderia violar diretamente as instâncias estruturais de ordem social diferenciada. É uma referência a esses dois riscos e à dupla função de contê-los que possuem os direitos fundamentais de que Luhmann chama respectivamente de "direito de liberdade" e "direito de igualdade" (Luhmann, 2002, p. 245).

Por consequência, em virtude do elevado nível de complexidade que vem permitindo e implementando, pela primazia do processo de diferenciação funcional da sociedade, é claro que uma condição de permanente equilíbrio entre estes dois riscos é não apenas impossível como inconcebível. E mais, o conflito entre estas duas instâncias - da liberdade e da igualdade - e suas recíprocas limitações representa um papel positivo. Compreende-se o princípio do disestablishment como um direito à liberdade e o free exercise como um direito à igualdade, tanto a história da gestão pública quanto a da gestão judicial das duas cláusulas da primeira emenda constitucional como é sabido, história complexa e rica da alternância entre tendências de sinal oposto - ganha, na nossa visão, um significado sociológico mais claro e completamente não contraditório.

Resumindo, por meio da teoria de Luhmann, é possível interpretar as primeiras duas cláusulas (as chamadas religious clauses) da primeira emenda constitucional dos Estados Unidos como outros tantos elementos constitutivos (ainda que em permanente tensão entre eles) de uma determinada compreensão daquele direito fundamental na base do sistema original de relação Estado/Igreja que é a religious freedom norte-americana. A compreensão 
particular desse direito, expressa nas duas religious clauses, é uma passagem fundamental do processo de acoplamento estrutural entre sistema político e sistema judiciário. Não por erro, atribui-se a ele um importante papel na fundação e definição da sociedade norte-americana. Essa instituição terá um papel fundamental na definição das relações Estado/Igreja (ou política/ religião) e justamente tornar-se-á também objeto de um específico acoplamento estrutural entre sistema político e sistema religioso ${ }^{11}$. Porém, para compreender corretamente essas relações nessa sociedade, é importante não negligenciar o fato de que essa instituição começou seu caminho pela sociedade e pela história americana talvez ou também sobretudo como instituição compartilhada pelo sistema político e pelo sistema judiciário. $\mathrm{O}$ fato de o debate político e jurídico a partir do qual a primeira emenda constitucional toma forma e afirma-se ser profundamente marcado pela influência de argumentos religiosos e teológicos (de varias matrizes cristãs, sustentados por fiéis e não fiéis) não muda em nada tudo que foi anteriormente afirmado (Diotallevi, 2010, p. 61 et seq.).

Tentaremos resumir brevemente a hipótese há pouco citada, identificando nela três elementos. 1) Com Luhmann, mesmo que não apenas com sua contribuição, é possível interpretar o princípio do disestablishment como direito à liberdade e o princípio do free exercise como direito à igualdade. A combinação dos dois é o que Luhmann chama Grundrechte, ou seja, uma instituição capaz de concorrer - como e com os outros direitos fundamentais dos indivíduos - seja à manutenção de certos níveis e certas formas de diferenciação da sociedade, principalmente de diferenciação entre subsistemas político e judiciário, seja à manutenção de um elevado grau de respeito por parte do sistema político para a liberdade e a dignidade individual no âmbito

${ }^{11} \mathrm{O}$ produto deste acoplamento estrutural é também destinado a atuar um papel global, tanto em âmbito político quanto no âmbito judiciário, como ainda em âmbito religioso e outros. Para o Catolicismo Romano, isto torna-se definitivamente evidente com o Concílio Ecumênico Vaticano II e a declaração sobre a liberdade religiosa Dignitatis humanae (1965).

Debates do NER, Porto Alegre, Ano i6, N. 27, P. I9-48, JAn./Jun. 2015 
religioso e com referências a questões religiosamente relevantes (Luhmann, 2002, p. 244 et seq.). 2) O espanto ou até mesmo o escândalo pela relação conflituosa e, não raro, propriamente contraditória entre os dois princípios (disestablishment e free exercise) depende de um defeito de compreensão sociológica ${ }^{12}$ das tensóes e dos riscos produzidos - junto a uma excepcional dose de oportunidade - pela primazia (sobre outras formas de diferenciação social) da diferenciação por funções da sociedade e pelo notável aumento relacionado da diferenciação entre domínio do social e domínio do pessoal ${ }^{13}$. Organizando-se, nunca estável nem pacificamente, conforme prescrito pelas duas cláusulas, desenvolve a dupla função daquela instituição que consiste em uma versão particular da liberdade religiosa. 3) Neste regime de relação Estado/Igreja, a instituição da liberdade religiosa é certamente objeto de um acoplamento estrutural entre subsistema político e subsistema religioso, mas também, e em certo sentido ainda antes, e necessariamente, de um acoplamento estrutural entre subsistema político e subsistema judiciário. É precisamente esta a condição graças a qual se pode falar de liberdade religiosa como um direito fundamental. Em essência, no regime americano de religious freedom, as relações Estado/Igreja não podem subsistir sem que se desenvolva certo tipo de relação entre política e direito. A este ponto está disposto o necessário para voltar ao confronto entre separatismo francês e separatismo norte-americano.

12 J. Maclure e C. Taylor (2013, p. 23-24), por exemplo, encontram esse problema quando observam que a exigência de separar Estado e Igreja pode impor o recurso a princípios que na prática podem se revelar em contraste ou até em contradição entre si, mas o tratam como um caso normal de descarte entre ideal e contingente, entre princípios e prática.

${ }^{13}$ De modo muito claro, Simmel (1982) já havia identificado o acoplamento entre o processo de diferenciação (em particular do tipo funcional) e o processo de individualização.

Debates do NER, Porto Alegre, ANo i6, N. 27, P. I9-48, JAN./Jun. 2015 


\section{O PAPEL DO DIREITO NA DEFINIÇÃO DO ESPAÇO PÚBLICO}

Ainda que longe de se esgotar, já foi lembrado como, nos casos americano e francês, se dá uma regularização profundamente diferente das relações entre organizações políticas e organizações religiosas e, por isso, entre poderes políticos e poderes religiosos. Além disso, a hegemonia garantida ao Estado na França, também com referência à religião (herança evidente de cuius regio eius et religio sancionado em Westfália) é simplesmente impossível e até mesmo impensável nos Estados Unidos da América ${ }^{14}$ (Fox, 2009; Philpott, 2009; Toft; Philpott; Shah, 2011). A hipótese que apresentamos, então, é a de compreender - com o recurso de Luhmann - a diferença entre os dois regimes também como a diferença entre os dois casos de acoplamento estrutural entre subsistema religioso e subsistema político realizados em objetos, ou seja, em instituiçôes de conteúdo e de perfil bastante diferentes entre elas.

Como se viu, na sociedade norte-americana, o tipo de acoplamento estrutural explicitado em nível constitucional pelas duas primeiras clauses do American Bill of Rights não fornece somente uma forma original para a relação entre o sistema político e o sistema religioso. Mesmo antes que a mesma instituição emerja no âmbito de um particular regulamento das relaçōes entre sistema político e sistema judiciário, uma regularização muito diferente do que aquele institucionalizado no âmbito do french statism. De fato, a partir de uma perspectiva sociológica, estamos nos referindo, mais ou menos, à mesma diferença a que se referem os juristas e cientistas políticos quando eles distinguem os sistemas de common law daqueles de civil law e, mais em geral, os casos caracterizados por modelos político-legais de rule of law em comparação aos caracterizados por modelos de Etat de droit ou Rechtsstaat (Zolo, 2003, p. 23-26; Costa, 2003, p. 120 et seq.; Luhmann, 2002, p. 83, nota 7).

\footnotetext{
${ }^{14}$ Não por acaso, o que coloca em crise a laicidade (ou "secularism") é a crise do Estado bem mais que o simples "retorno da religião" (Modood, 2013, p. 132; ver também Diotallevi, 2010).
} 
Em última análise, o que emerge é que o sistema religious freedom somente se forma fora da tradição inaugurada em Westfália de reação e de limitação da diferenciação das "esferas sociais" (Creppell, 2010; Turner, 2011, p. 150) e fora de qualquer pretensão de soberania ou mesmo da neutralidade formal do poder político (Laycock, 2010, p. 229-230, p. 241). Ao contrário, é parte da tradição de submissão do direito e da religião à política ${ }^{15}$. Vários podem ser os sinais que a literatura oferece como apoio da decisão de aprofundar ainda uma hipótese como essa recém-exposta. S. V Monsma ressaltou como seria impossível construir uma orientação de "substantive neutrality" fora de um contexto de rule of law (Laycock, 2010). Com o auxílio de Luhmann, somos capazes de distinguir os dois separatismos, o francês e o norte-americano, reconduzindo-os a duas estruturas marcadamente diferentes de diferenciação social. Em especial, podemos entender melhor que a separação entre política e religião, mesmo permanecendo assim, muda profundamente, dependendo das relações que se aplicam entre política e direito (e obviamente entre religião e direito).

Ainda outro elemento esclarece-se, uma vez que a diferença entre o sistema de religious freedom e o de lä̈cité é interpretado como uma expressão qualificada de uma notável diferença entre graus e entre formas de diferenciação funcional da sociedade. De fato, nesta perspectiva, é possível afirmar que somente no caso de uma sociedade em que a diferenciação funcional impulsionou bem para frente uma retomada de influência sobre a política por parte da religião e, mais genericamente, sobre o espaço público, não é necessariamente uma indicação de de-diferenciá-la, nem muito menos de

${ }^{15}$ Quando tudo isso escapa ou é ignorado, e os dois separatismos são assimilados (como faz Baubérot ou como fazem os próprios Maclure e Taylor, já mencionados), geralmente acontece que, tendo por objetivo defender uma versão, talvez moderada, de laicidade, é a este regime que se reconduz o outro, negligenciando todas as características que pelo contrário resistem a essa operação. Entre tantas dessas, destaca-se a ausência por parte da política de exigências como as que ela possui no regime de lä̈cité.

Debates do NER, Porto Alegre, ano i6, N. 27, P. I9-48, JAN./Jun. 2015 
crises da modernidade (Jelen, 2010; Luhmann, 2002, p. 277-278) ${ }^{16}$. No outro caso, no entanto, o de uma sociedade em que a primazia organizada da política (O Estado, no sentido europeu-continental do termo) desacelerou e deformou a primazia da diferenciação funcional, a eventual retomada de influência da religião sobre política e sobre o espaço público em geral possui um significado ambíguo. Por um lado, contesta-se que a primazia da política, sem pretender substituí-la ${ }^{17}$, pode ser interpretada como impulso para um avanço da modernização em sua tendência original em direção a uma sociedade sem centro e sem vértice (Luhmann). Por outro lado, se ao contrário não contesta, mas tem competência para retirar a primazia da política, então manifesta-se efetivamente como um impulso de de-diferenciação, como impulso involutivo e antimoderno. ${ }^{18}$

Por fim, para compreender a diferença entre o separatismo francês e o separatismo norte-americano, não devemos simplesmente nos concentrar nas relações entre política e religião, mas também e talvez ainda nas relações entre política e direito, bem como aquelas entre essas duas realidades e religião.

Com o auxílio de Luhmann, não podemos compreender os dois separatismos - o norte-americano e o francês - como manifestações parciais mas decisivas de duas formas muito diferentes (mais radical que a norte-americana, e menos que a francesa) e como dois graus (mais elevado que a

${ }^{16}$ Certamente, um caso normal em que o ambiente de um subsistema funcionalmente especializado e diferenciado, ou - entre o outro - outros subsistemas diversamente especializados e analogamente diferenciados, irrita aquele subsistema particular. Irrita, talvez provoca nele uma reação, mas não traz à discussão a autonomia, e - normalmente - nem requer sua reprodução.

${ }^{17}$ Um bom exemplo dessa atitude foi oferecido pelo discurso sustentado no Bundestag, em 2010, pelo Papa Ratzinger (Bento XVI). A contestação da exigência do Estado de dispor dos direitos e defini-los autonomamente não é contestada em nome de uma exigência equivalente e alternativa por parte da religião cristã, mas em vista de uma busca comum e contínua.

${ }^{18}$ Este critério poderia orientar uma releitura da obra já clássica de J. Casanova (2000): os exemplos de retomada de influência da religião sobre a política são de que tipo?

Debates do NER, Porto Alegre, Ano i6, N. 27, P. I9-48, JAn./Jun. 2015 
norte-americana e menos que a francesa) da primazia da diferenciação funcional da sociedade sobre outras formas de diferenciação social ${ }^{19} . \mathrm{Na}$ verdade, no caso francês (e em geral na Europa-continental), as formas e o grau obtidos pelo processo de diferenciação funcional da sociedade não são nem suficientemente radicais nem elevadas o suficiente para evitar qualquer tipo de hegemonia e de controle exercido por organizaçôes políticas e, em particular, por parte do Estado em relação às organizações religiosas como de resto sobre as outras organizaçóes sociais, incluindo as do sistema judiciário.

\section{UMA ANÁLISE PARA PROSSEGUIR}

Os sistemas de läcité e de religious freedom separam de formas muito diferentes a Igreja e o Estado. Em ambos os casos, é possível falar de separatismo radical e secularismo radical, mas fazendo isso permanece ainda na sombra uma diferença muito profunda.

O separatismo da religious freedom tem por escopo preservar a diferenciação funcional da sociedade, o separatismo da lä̈cité, ao contrário, tem por escopo contê-la, reduzi-la, negá-la ao máximo. O primeiro separatismo é poliárquico, e o segundo é monárquico (Stepan, 2000; Witte, 2000, p. 45-46). O primeiro é uma forma de garantir as condiçôes institucionais de uma stateless society, o segundo de uma state society (Stepan, 2011, p. 215; Jensen, 2011, p. 19). Pressupóem orientações muito diferentes umas das outras nas comparações de uma elevada autonomia dos outros subsistemas sociais a partir do econômico, científico e familiar, e primeiramente nas comparações de um elevado grau de autonomia por parte do sistema

19 Trata-se, neste caso, de uma estratégia interpretativa completamente diferente da adotada por quem (ver, por exemplo, Maclure Taylor, 2013, p. 18) pensa que a separação de política e religião se desenvolve ao longo da linha que separa as instituições (da política) das consciências dos indivíduos. Na hipótese aqui seguida, a separação Estado/Igreja é, em vez disso, reconduzida a uma separação entre as instituições e não só, ou mesmo antes de tudo, a uma separação de instituições das consciências.

Debates do NER, Porto Alegre, ANo i6, N. 27, P. I9-48, JAN./Jun. 2015 
judiciário e da administração do direito. Em suma, para recorrer à expressão de Monsma, os dois sistemas determinam bem e diferentemente o campo de jogo no qual se confrontam Igreja e Estado, organizações religiosas e organizações políticas ${ }^{20}$.

O espaço disponível permite apenas, muito brevemente, esboçar duas outras vantagens analíticas ${ }^{21}$ que a análise sociológica pode, de bom senso,

${ }^{20}$ A partir deste ponto, poderia, ou talvez deveria, retomar os movimentos não somente de um mais atento reconhecimento da multiplicidade das secularities - das quais la laïcité permanece um caso cada vez mais marginal e frágil. (Modood, 2012, p. 64 et seq.; Calhoun; Juergenrmeyer; Van Antwerpen, 2011, p. 8-12; Casanova, 2011, p. 56), mas uma reconsideração da originária ambivalência do saeculum (em uma direção similar à traçada, e certamente não esgotada, por R. A. Markus, 1970; 2006). Para algumas tentativas recentes neste sentido, veja Cacciari, 2013 e Diotallevi, 2013.

${ }^{21}$ Entre os desenvolvimentos dos quais não é possível sequer fazer uma menção de algumas linhas, há o que diz respeito ao aparecimento dos agentes religiosos no campo visual dos estudos dedicado às IIRR. Em uma global polity não mais feita somente de Estados e de relaçôes entre Estados, e na qual o Estado está portanto em profunda crise (no sentido próprio e da Europa continental do termo) e as state societies das quais a laicidade é uma qualidade decisiva, não é um acaso que os dois modelos de separação entre as organizações religiosas e organizaçôes políticas sobre as quais nós nos detemos aqui nesta sede funcionam de modo bem diferente. Nem é por acaso que alguns agentes religiosos já sejam considerados entre os protagonistas do espaço público global (Fox, 2009; Philipott, 2009).

Um outro desenvolvimento possível diz respeito mais diretamente ao caso italiano. Adotando a perspectiva aqui proposta, pode aparecer com maior clareza qual é a capacidade da mudança introduzida pela sentença 203/1898 da Corte Constitucional. Essa sentença apresentou a laicidade como um eminente princípio constitucional com referência a uma Carta na qual não há um traço de laicidade, nem como termo e tão pouco como modelo. Para uma apresentação certa e não crítica da novidade introduzida pela sentenza, pense-se às críticas de juristas como A. Barbera ou G. Dalla Torre (Ferrari, 2012, p. 122-128). Efeito disso, a equiparação do ateísmo à qualquer posição religiosa completa a tentativa, já muito avançada, de reduzir a liberdade religiosa a um caso entre os muitos de liberdade de consciência.

Debates do NER, Porto Alegre, Ano i6, N. 27, P. I9-48, JAn./Jun. 2015 
esperar para ser usada em uma escala maior do que resultou útil para distinguir o regime separatista de lä̈cité pelo regime separatista de religious freedom.

A diferença entre os separatismos radicais francês e norte-americano não é somente uma diferença profunda, é também uma diferença que não esgota sua relevância neste âmbito. É uma diferença que pode ajudar a colocar um pouco de ordem na superlotada categoria do "secularismo moderado". O regime separatista da religious freedom que institucionaliza a diferenciação entre o sistema político e o sistema judiciário, como se viu, institucionaliza também uma diferenciação funcional análoga entre o sistema político e religioso e entre este e o sistema judiciário. Tudo isso é parte e expressão qualificada de formas muito radicalizadas e generalizadas de diferenciação funcional da sociedade. Estas não admitem mais nenhuma forma de acoplamento organizado e menos ainda de regularização para hierarquização das relações sistema político, sistema judiciário e sistema religioso. Em suma, é correto afirmar que essa versão de liberdade religiosa é uma instituição decisiva de ordem social que garante o que Luhmann denomina de falta de organização da sociedade como um todo (Unorganisieberkheit der Gesellschaft). Contrariamente, no caso francês, é uma versão significativamente diferente da liberdade religiosa para presidir institucionalmente a diferenciação entre o sistema político e o sistema religioso. Essa versão da liberdade religiosa supõe, diferentemente da outra, uma substancial e efetiva supremacia do sistema político sobre o sistema judiciário, bem como um rígido controle por parte da política do acesso - nos casos em que é concedido - pela religião ao espaço público. Essa versão francesa da liberdade religiosa, que passa sob o rótulo de laïcité, resulta completamente funcional no projeto de uma organização política da sociedade, que se realiza na forma do Estado. A versão lä̈que da liberdade religiosa é uma instituição dedicada a parar ou conter o processo de diferenciação funcional da sociedade. Em suma, sociologicamente falando, os dois separatismos são instituições complexas que servem como componentes essenciais das duas polities profundamente diferentes. Tanto em um como em outro regime, é possível observar casos de cooperação entre Estado e Igreja, entre organizaçôes do sistema político 
e organizações do sistema religioso. O conceito de cooperação acaba, assim, por referir-se a muitas coisas diferentes entre si. Por maior razão, fatalmente, o mesmo acontece para a categoria do "secularismo moderado", ou de "separatismo moderado", que se refere a casos cada vez mais numerosos, em que a cooperação entre o Estado e a Igreja alcança maior frequência, e os volumes são bem mais elevados do que na França ou nos Estados Unidos. Se, no entanto, assume-se a perspectiva analítica adotada neste momento e se a usa como critério de discernimento, torna-se possível distinguir entre tipos muito diferentes de cooperação entre Estado e Igreja (Baeckstroem; Davie, 2010, p. 183 et seq.) e, portanto, entre tipos muito diferentes de "moderate secularism" ou de "moderate separatism". No caso do regime de religious freedom, a cooperação que se desenvolve em cada caso é ou pode sempre ser também uma competição (tais como a relação entre a autonomia que reciprocamente se reconhecem como tal). No caso do regime de lä̈cité, isso não pode jamais ocorrer, pelo menos em princípio. Em uma sociedade em que a diferenciação funcional atingiu níveis elevados e formas radicais e na qual a função é um regime religious freedom, a cooperação entre organizações religiosas e organizações políticas, que seja rara ou frequente, desenrola-se em um espaço público no qual nenhum dos dois tipos de agentes atua como um senhorio ou como senhor. Isto é, porém, precisamente o que ocorre nos regimes de laïcité. Aqui, a cooperação entre organizações religiosas e organizaçóes políticas acontece em um espaço público dominado e controlado pelo Estado ou por uma organização política. Que o mesmo se encontre na primeira ou na segunda situação, depende, se não totalmente, da medida relevante da condição de maior ou menor autonomia em que o sistema judiciário se encontra em relação ao sistema político (e ao sistema religioso). É muito provável que um critério útil para distinguir entre formas muito diferentes de cooperação entre organizações religiosas e organizações política possa operar com sucesso mesmo se aplicado aos casos que acabam no tipo "separatismo moderado". Ainda, dados os números muito maiores deste grupo, a tendência em prática que os vê em crescimento e o volume muito maior de cooperação que os caracteriza, é exatamente neste último tipo 
que o uso do critério aqui proposto parece mais urgente e mais promissor. Em resumo, se se adota o critério proposto, pode-se evitar que a tipologia das relaçôes Estado-Igreja continue a produzir um grupo de dimensôes já muito grandes e que, além disso, corre o risco de logo reunir todos ou quase todos os casos.

Por fim, a hipótese seguida até aqui promete revelar-se útil ao menos em uma segunda direção. $\mathrm{O}$ enfoque luhmanniano permite também apreciar as raízes britânicas do modelo norte-americano - emersas, antes de mais nada, com o êxito da Glorious Revolution (Diotallevi, 2010, p. 142 et seq.; Zolo, 2003, p. 29; Santoro, 2003, p. 184-213). Ao mesmo tempo, consente evitar e confundir o particular establishment inglês com o das Igrejas de Estado Luteranas do Norte da Europa ou com certos casos de Estados confessionais católicos (Hill, 2010, p. 162; Dibdim, 1932, p. 109-112). Assim, torna-se possível reconhecer e apreciar devidamente a presença da variante britânica da história da Europa das relações Estado/Igreja. Isto torna absolutamente impossível reduzir essa história somente ao modelo da lä̈cite ${ }^{22}$. Por outro lado, e exatamente por esta última razão, torna-se mais claramente manifesto o caráter laicizante de muitas das decisões e das políticas assumidas por numerosas expressóes da União Europeia (Doe, 2010, p. 151 et seq.; Hill, 2010, p. 169 et seq.; Houston, 2010; Scolnicov, 2010). Elas tendem não a já representarem, como pretenderiam, mas a produzir uma única e homogênea e, nestes termos, na verdade, completamente inédita identidade europeia ${ }^{23}$. Tais decisões e tais políticas tendem a negar e esconder a variedade das tradições, todas igualmente europeias na área das relações Estado/ Igreja, e a fazê-lo em nome e por causa da lä̈cité ou de apenas uma dessas tradições. Não se sabe se, de uma forma mais dramática ou mais irônica, isso

${ }^{22}$ Sem com isso afirmar que se trata de um modelo não submetido a tensões e a transformações, ao contrário muito evidentes, e o sucesso totalmente incerto (Rivers, 2012).

${ }^{23}$ Ver Ferrari, 1999, p. 3. Mais recentemente, o autor propõe uma imagem diferente e menos homogênea da presença e do papel da religiāo no espaço público na Europa (Ferrari, S., 2012). 
verifica-se no exato momento em que a laïcité se revela empiricamente um modelo cada vez mais marginal e declinante, no momento em que revela estar inevitavelmente envolvido em uma crise cada vez mais radical, que é, por outro lado, a crise do Estado e das state societies.

Figura 1 - Lä̈cité e religious freedom: representação esquemática da diferença entre os dois separatismos.

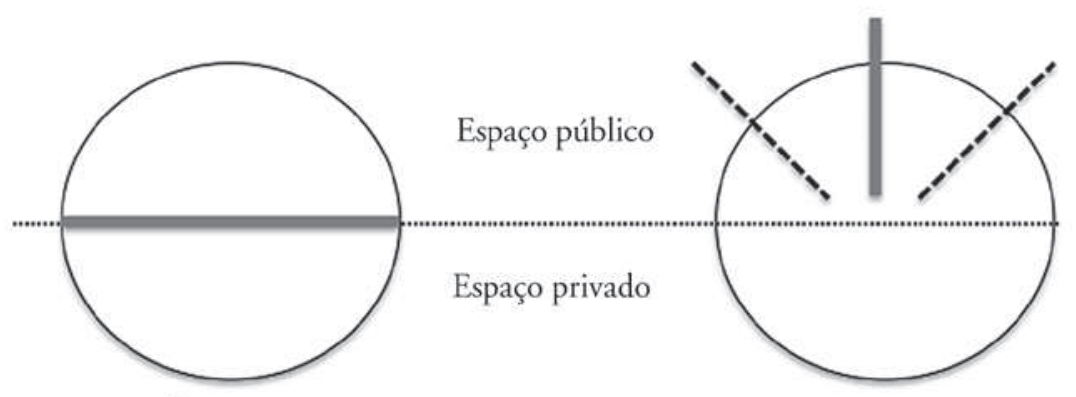

Legenda: o "muro de separação" entre poder político e poder religioso. 


\section{REFERENNCIAS}

AHDAR, Rex; LEIGH, Ian. Religious freedom in the Liberal State. Oxford: Oxford University Press, 2005.

BAECKSTROEM, Anders; DAVIE, Grace. A Preliminary Conclusion: Gathering the Threads and Moving On. In: BAECKSTROEM, Anders; DAVIE, Grace; EDGARDH, Ninna; PETTERSON, Per (Ed.). Welfare and Religion in 21st Century Europe: Volume 1. Farnham: Ashgate, p. 183-198, 2010.

BAUBÉROT, Jean. Le tante laicità del mondo. Roma: Luiss University Press, 2008.

BECKFORD, James. 'Laïcité, 'Dystopia', and the Reaction to new Religious Movements in France. In: RICHARDSON, J. T. (Ed.). Regulating Religion. New York: Kluwer, p. 27-40, 2004.

BEYER, Peter. Socially Engaged Religion in a Post-Westphalian Global Context: Remodeling the Secular/Religious Distinction. In: ASR ANNUAL MEETING, 73, 2011, Las Vegas. 73rd Annual Meeting. Tampa, FL: ASR, 2011. p. 109-130.

CACCIARI, Massimo. Il potere che frena. Milano: Adelphi, 2013.

CALHOUN, Craig; JUERGENSMEYER, Mark; VAN ANTWERPEN, Jonathan. Introduction. In: Rethinking Secularism. Oxford: Oxford

University Press, p. 3-30, 2011.

CASANOVA, José. Oltre la secolarizzazione. Bologna: Il Mulino, 2000.

The Secular and Secularisms. Social Research, New York, v. 76, n. 4, p. 1049-1066, 2009.

. The Secular, Secularizations, Secularisms. In: CALHOUN, Craig; JUERGENSMEYER, Mark; VAN ANTWERPEN, Jonathan. Rethinking Secularism. Oxford: Oxford University Press, p. 54-74, 2011.

Debates do NER, Porto Alegre, ANo i6, N. 27, P. I9-48, JAN./Jun. 2015 
CASSESE, Sabino. Lo stato introvabile. Roma: Donzelli, 1998. Chi governa il mondo? Bologna: Il Mulino, 2013.

COMMISSIONE STASI. Rapporto sulla laicità. Milano: Libri Scheiwiller, 2004.

COSTA, Pietro. Lo Stato di diritto: un'introduzione storica. In: COSTA, Pietro; ZOLO, Danilo (Ed.). Lo Stato di diritto: Storia, teoria e critica. Milano: Milano, p. 89-172, 2003.

CREPPELL, Ingrid. Secularisation: religion and the roots of innovation in the political sphere. In: KATZNELSON, Ira; STEDMAN JONES, Gareth (Ed.). Religion and the Political Imagination. Cambridge, UK: Cambridge University Press, p. 23-45, 2010.

DIBDIN, Sir Dean. Establishment in England: Essays on Church and State. London: McMillan and Co., 1932.

DIOTALLEVI, Luca. Church-State relations in Catholic Europe and the Crisis of the European Social Model In: MOTZKIN, Gabriel; FISHER, Yochi (Ed.). Religion and democracy in contemporary Europe. v. 1. London: The Van Leer Jerusalem Institute \& NEF, p. 125-140, 2007.

Una alternativa alla laicità. Soveria Mannelli, CZ: Rubbettino, 2010. La pretesa. Quale rapporto tra vangelo e ordine sociale. Soveria Mannelli, CZ: Rubbettino, 2013.

DOE, Norman. Towards a 'Common Law' on Religion in the European Union. In: LEUSTEAN, Lucian; MADELEY, John (Ed.). Religion, Politics and Law in the European Union. London: Routledge, p. 141-160, 2010. . Law and Religion in Europe: A Comparative Introduction. Oxford: Oxford University Press, 2011. 
ENYEDI, Zsolt. Conclusion: Emerging Issues in the Study of Church-State Relations. In: MADELEY, John (Ed.). Church and state in contemporary Europe: The Chimera of neutrality. London: Frank Cass, p. 218-232, 2003.

FERRARI, Alessandro. La libertà religiosa in Italia: Un percorso incompiuto. Roma: Carocci, 2012.

FERRARI, Silvio. The new wine and the old cast: tolerance, religion, and the law in contemporary Europe. In: SAJÒ, Andras; AVINERI, Shlomo (Ed.). The Law of Religious Identity: Models for Post-Communism. The Hague: Kluwer Law International, p. 1-16, 1999.

Law and Religion in a Secular World: A European Perspective. Ecclesiastical Law Journal, Cambridge, UK, v. 14, n. 3, p. 355-370, 2012.

FINKE, Roger. Origins and Consequences of Religious Freedoms: A Global Overview. Sociology of Religion, v. 74, n. 3, p. 297-313, 2013.

FOX, Jonathan. World Separation of Religion and State Into the 21st Century. Comparative Political Studies, v. 39, n. 5, p. 537, 2006.

. Integrating religion into international relations theory. In: HAYNES, Jeff (Ed.). Routledge Handbook of Religion and Politics. London: Routledge, p. 273-292, 2009

GORSKI, Philip. Historicizing the secularization debate: Church, State, and Society in late Medieval and Early Modern Europe, ca. 1300 to 1700. American Sociological Review, v. 65, n. 1, p. 138-167, 2000.

HAYNES, Jeffrey. Religion and politics in Europe, the Middle East and North Africa. In: (Ed.). Religion and politics in Europe, the Middle East and North Africa. London: Routledge, p. 1-20, 2010.

HILL, Mark. Voices in the Wilderness: the Established Church of England and the European Union. In: LEUSTEAN, Lucian; MADELEY, John (Ed.). Religion, Politics and Law in the European Union. London: Routledge, p. 161-174, 2010.

Debates do NER, Porto Alegre, ANo i6, N. 27, P. I9-48, JAN./Jun. 2015 
HOUSTON, Kenneth. The Logic of Structured Dialogue between Religious Associations and the Institutions of European Union. In: LEUSTEAN, Lucian; MADELEY, John (Ed.). Religion, Politics and Law in the European Union. London: Routledge, p. 201-216, 2010.

JELEN, Ted. Religious Liberty as a Democratic Institution. In: DAVIS, Derek (Ed.). Church and State in the United States. Oxford: Oxford University Press, p. 311-329, 2010.

JENSEN, Darryn. Classifying church-state arrangements. Beyond religious versus secular. In: HOSEN, Nadirsyah; MOHR, Richard (Ed.). Law and Religion in Public Life: The contemporary debate. London: Routledge, p. 15-33, 2011.

JEPPERSON, Ronald. Ordine pubblico e costruzione di organizzazioni formali. In: POWELL, Walter; MEYER, John; DIMAGGIO, Paul (Ed.). Il neoistituzionalismo nell'analisi organizativa. Torino: Edizioni di Comunità, p. 275-312, 2000.

Political Modernities: Disentangling Two Underlying Dimensions of Institutional Differentiation. Sociological Theory, v. 20, n. 1, p. 61-85, 2002.

KLAUSEN, Jytte. Why religion has become more salient in Europe: four working hypotheses about secularization and religiosity in contemporary politics. European political science, v. 8, p. 289-300, 2009.

KURU, Ahmet. Passive and Assertive Secularism. Historical Conditions, Ideological Struggles, and State Policies toward Religion. World Politics, Cambridge, UK, v. 59, p. 568-594, 2007.

LAYCOCK, Douglas. Substantive Neutrality Revisited. In: Religious Liberty: Volume One. Grand Rapids: Eerdmans, p. 225-267, 2010.

LILLO, Pasquale. Globalizzazione del diritto e fenomeno religioso. Torino: Giappichelli, 2012. 
LUHMANN, Niklas. Funktion der Religion. Frankfurt: Suhrkamp, 1977. . La differenziazione del diritto. Bologna: Il Mulino, 1990. . Das recht der gesellschaft. Frankfurt: Suhrkamp, 1995. . Die Gesellchaft der Gesellchaft. v. 2. Frankfurt: Suhrkamp, 1997. . I diritti fondamentali come istituzione. Bari: Dedalo, 2002. . Organizzazione e decisione. Milano: Bruno Mondadori, 2005.

MACLURE, Jocelyn; TAYLOR, Charles. La scommessa del laico. Roma/ Bari: Laterza, 2013.

MADELEY, John. European liberal democracies and the principle of state religious neutrality. In: Church and state in contemporary Europe: The Chimera of neutrality. London: Frank Cass, p. 1-22, 2003. . Unequally yoked: the antinomies of church-state separation in Europe and the USA. European political science, v. 8, p. 273-288, 2009.

MARKUS, Robert. Saeculum: History and Society in the Theology of ST Augustin. Cambridge, UK: Cambridge University Press, 1970.

. Christianity and the secular. Notre Dame: University of Notre Dame Press, 2006.

McCONNELL, Michael. Reclaiming the Secular and the Religious: The Primacy of Religious Autonomy. Social Research, New York, v. 4, p. 1333-1344, 2009.

MODOOD, Tariq. Muslims, religious equality and secularism. In: LEVEY, Geoffrey B.; MODOOD, Tariq (Ed.). Secularism, Religion and Multicultural Citizenship. Cambridge, UK: Cambridge University Press, p. 164-185, 2009. Is There a Crisis of Secularism in Western Europe? Sociology of Religion, v. 73, n. 2, p. 130-149, 2012 a.

. Moderate secularism, religion as identity and respect for religion. In: REED, Esther; DUMPER, Michael (Ed.). Civil liberties, national security and prospects for consensus. Cambridge, UK: Cambridge University Press, p. 62-80, 2012 b. 
MONSMA, Stephen. Substantive Neutrality as a Basis for Free ExerciseNo Establishment Common Ground. Journal of Church \& State, Oxford, winter 2000, v. 42, n. 1, p. 13-36, 2000.

NANCY, Jean-Luc. Church, State, Resistance. Journal of Law and Society, Cardiff, v. 34, n. 1, p. 3-13, 2007.

PHILIPPOPOULOS-MIHALOPOULOS, Andreas. Niklas Luhmann: Law, Justice, Society. London: Routledge, 2011.

PHILPOTT, Daniel. Has the Study of Global Politics Found Religion? Annual Review of Political Science, Palo Alto, CA, v. 12, p. 183-202, 2009.

POGGI, Gianfranco. Lo Stato. Bologna: Il Mulino, 2007.

RAHMAN, Fatima. The Effects of State-Established Religion on Religious Freedom for Minorities. Interdisciplinary Journal of Research on Religion, Waco, TX, v. 9, p. 1-24, 2013.

RIVERS, Julian. The Secularization of the British Constitution. Ecclesiastical Law Journal, Cambridge, UK, v. 14, n. 3, p. 371-399, 2012.

ROUSSEAU, Jean-Jacques. Il contratto sociale. Milano: Mursia, 1974.

SANTORO, Emilio. "Rule of law" e "libertà degli inglesi". L'interpretazione di Albert Venn Dicey. In: COSTA, Pietro; ZOLO, Danilo (Ed.). Lo Stato di diritto: Storia, teoria e critica. Milano: Feltrinelli, p. 173-223, 2003.

SCOLNICOV, Anat. Does constitutionalisation lead to secularisation? The case law of the European Court of Human Rights and its effect on European secularization. In: KATZNELSON, Ira; STEDMAN JONES, Gareth (Ed.). Religion and the Political Imagination. Cambridge, UK: Cambridge University Press, p. 295-313, 2010.

SIMMEL, Georg. La differenziazione sociale. Roma/Bari: Laterza, 1982. 
STEPAN, Alfred. The Multiple Secularisms of Modern Democratic and Non-Democratic Regimes. In: CALHOUN, Craig; JUERGENSMEYER, Mark; VAN ANTWERPEN, Jonathan. Rethinking Secularism. Oxford: Oxford University Press, p. 114-144, 2011.

Religion, Democracy, and the "Twin Tolerations". In: DIAMONS, Larry; PLOTTNER, Marc F; COSTOPULOS, Philip J. World Religions and Democracy. Baltimore: John Hopkins University Press, p. 37-57, 2000.

. Arguing Comparative Politics. Oxford: Oxford University Press, 2001.

TOFT, Monica; PHILPOTT, Daniel; SHAH, Timothy. God's Century: Resurgent Religion and Global Politics. New York: Norton \& Company, 2011.

TURNER, Bertram; KIRSCH, Thomas. Law and Religion in Permutation Order: An Introduction. In: (Ed.). Permutations of Order: Religion and Law as Contested Sovereignties. Farnham: Ashgate, p. 1-26, 2009.

TURNER, Bryan. Religion and Modern Society: Citizenship, Secularization and the State. Cambridge, UK: Cambridge University Press, 2011.

VALASIK, Corinne. Church-State Relations in France in the Field of Welfare: A Hidden Complementarity. In: BAECKSTROEM, Anders; DAVIE, Grace; EDGARDH, Ninna; PETTERSON, Per (Ed.). Welfare and Religion in 21st Century Europe: Volume 1. Farnham: Ashgate, p. 129-145, 2010.

WITTE, John Jr. Religion and the American Constitutional Experiment: Essential Rights and Liberties. Boulder, CO: Westview, 2000.

WITTE, John Jr.; NICHOLS, Joel. Religion and the American Constitutional Experiment. Boulder, CO: Westview, 2011.

ZOLO, Danilo. Teoria e critica dello Stato di diritto. In: COSTA, Pietro; ZOLO, Danilo (Ed.). Lo Stato di diritto: Storia, teoria e critica. Milano: Feltrinelli, p. 17-88, 2003.

Recebido em: 06/03/2014

Aprovado em: 16/04/2014 